\title{
AC 2009-1788: PROJECT DESIGN PRINCIPLES AND APPLICATIONS USING UNIVERSAL DESIGN LEARNING (UDL)
}

\section{Saeed Monemi, California State Polytechnic University, Pomona}

Dr. Saeed Sean Monemi is currently a Professor and Graduate Program Chair of Electrical and Computer Engineering at California State Polytechnic University in Pomona, CA (Cal Poly Pomona). He is teaching a broad range of Undergraduate and Graduate level courses in electrical and computer engineering. His research areas are: Algorithms and Complex Computations, Energy Management Environments, Operating Systems, Software Engineering and Robotics. Before that, Dr. Monemi was Senior Associate Research Professor and Research Scientist at Vanderbilt University, where he conducted research in the areas of Model Integrated Computing, Diagnostics, and Fault Management Analysis. Dr. Saeed Sean Monemi received his B.S. in Electrical Engineering from Alabama A\&M University, his Master and Doctorate Degree in Electrical Engineering from Vanderbilt University.

\section{Weicong Pan, California State Polytechnic University, Pomona}

Mr. Weicong Pan is a senior udergraduate student in electrical and computer engineering department.

\section{Edward Varnado, California State Polytechnic University, Pomona}

Mr. Edward Varnado is a senior undergraduate student in electrical and computer engineering department. 


\title{
Project Design Principles and Applications Using Universal Design Learning (UDL)
}

\begin{abstract}
This paper will present a structured course in student's project design and applications using the concept of Universal Design Learning (UDL). Universal Design is an approach to designing course instruction, materials, and content to benefit people of all learning styles without adaptations or retrofitting. Universal design provides equal access to learning, not just simply equal access to information. Universal design allows the students to control the method of accessing information while the instructor monitors the learning process and initiates any beneficial methods.
\end{abstract}

\section{Introduction}

The concept of $\mathrm{UDL}^{1}$ was applied to a team senior project course. The course, EGR 481, Project Design Principles and Applications, was taught in fall 2008 using UDL concepts. EGR 481 is a required course for all engineers. Prerequisite for the course is that students must be at senior level. The course can be taught by either using UDL concept or not, the instructor will make that decision. Generally some information is contained in the course syllabus using UDL that specifies campus-based student support services, including disability support services. Multiple methods of expressing course content using innovative methods are provided so that students have varied ways to access the course content. Varied instructional methods using UDL are provided to engage students in the learning process throughout the quarter. Assessment and feedback on student's assignments along with some clear guidelines are provided to better address student's needs. Assistive technologies are encouraged for a clear result on student's expressions.

\section{Motivation for using UDL versus non-UDL based projects}

Project Design Principles and Applications course (EGR 481) was taught using UDL concepts. EGR 481 is a required course for all Engineers. Prerequisite for the course is that students must be at senior level and completed some pre-requisite courses. Students registering for this course can be either from any engineering disciplines or can also be from non-engineering majors. In either case, students may face some challenges ${ }^{2}$ that could be solved by using UDL concept. These challenges or concerns of most students can be summarizes as:

- Students are struggling:

- To be more pro-active

- Because of slow start on projects

- Because of lack of research interest

- To work together

- To understand transfer of technology from academia to industry

- Students are not knowing:

- How to allocate resources 
- How to schedule and manage time and resources (i.e. using MS project)

- How to make an assessment

- How to deal with risk management

- What will I be doing for students with disability?

- I will get them involve with the subject and make them proactive

- I will teach them how to work with others

- I will have them to celebrate the accomplishments

\section{Objectives of EGR 481 using UDL:}

One of the main objectives of this course is to come up with a new or revised course curriculum that utilizes the concept of an affordable design. This shall help any level of students including the students with disability and special needs. An E-team formed in the class will be able to plan, design, develop and implement some affordable projects using UDL concept. Students with multidisciplinary backgrounds such as mechanical, electrical, computer engineering, physics and business will be able to participate and build the project and discuss any difficulties encountered by group discussion and formal progress report and offer possible solutions to said difficulties. Students will create and update their time and resource schedules (may be using MS project or similar) in accordance with results just like the real world projects. Students will work on and complete their team project within the constraints stated in project proposal and finally write a formal final report and make presentation of the project along with a working prototype.

\section{Expectations of EGR 481 using UDL:}

Students enrolled in EGR 481 using UDL (versus non-UDL) are expected to be very proactive in their work, be a critical thinker, to focus on creation and innovation using UDL concept, and to communicate in all areas including multidisciplinary. They must perform well in team work (help others), being able to accommodate to those who cannot, possibly because of their disability, to understand concept of design and apply it their project, and finally to understand issues in transfer of technology from academia to industry.

\section{General course ideas:}

On the general side, a statement or information is contained in the course syllabus that specifies campus-based student support services, including disability support services. A comprehensive syllabus that clearly specifies all course requirements, course expectations and due dates is provided. Multiple forms of contact information so students have varied ways to contact the instructor with questions or concerns are offered as follows:

1. A statement or information is contained in the course syllabus that specifies campus-based student support services, including disability support services, for example:

"Anyone who needs an accommodation based on the impact of a disability should contact Disable Student Services at 909-869-3333 located in building 9, room 103”.

2. A comprehensive syllabus is provided that clearly specifies all course requirements, course expectations and due dates. The EGR 481 syllabus is as follows: 


\begin{tabular}{|c|c|c|}
\hline \multicolumn{3}{|c|}{ Course Syllabus: EGR 481 - Fall 08} \\
\hline Professor's name: & \multirow{5}{*}{\multicolumn{2}{|c|}{$\begin{array}{l}\text { Dr. S. Monemi } \\
\text { 9-527, 909-869-2520 } \\
\text { ssmonemi@ csupomona.edu } \\
\text { MW 1:00-1:50 PM, Room 9-329 } \\
\text { Upper division standing }\end{array}$}} \\
\hline Office location \& phone: & & \\
\hline Email: & & \\
\hline Class time and location: & & \\
\hline Course prerequisites: & & \\
\hline Office Hours: & Monday, Tuesday, Wednesday & 8:00 - 10:00 AM \\
\hline Textbook: & \multicolumn{2}{|l|}{ Class notes and handouts } \\
\hline Course Description: & \multicolumn{2}{|c|}{$\begin{array}{l}\text { Completion of a capstone senior design team project under } \\
\text { faculty supervision. Results are presented in a formal report. }\end{array}$} \\
\hline Course Coverage: & \multicolumn{2}{|c|}{$\begin{array}{l}\text { Learn how to design, develop, and analyze problems using } \\
\text { UDL. Completion of a detailed design for the multidisciplinary } \\
\text { team project, leading to implementation of the device/system. } \\
\text { To complete work on project and perform testing of the device } \\
\text { or system showing the operation of the device. To write and } \\
\text { present the final report. }\end{array}$} \\
\hline Course Objectives: & \multicolumn{2}{|c|}{$\begin{array}{l}\text { After completing this course the student will be able to: } \\
\text { 1) Benefits of the project using UDL concept. } \\
\text { 2) Write formal progress reports stating progress made, } \\
\text { difficulties encountered, and possible solutions to } \\
\text { difficulties, and to update time schedules. } \\
\text { 3) Work in a multidisciplinary team environment and } \\
\text { complete his/her team project within the constraints stated } \\
\text { in his/her project proposal. } \\
\text { 4) Lear how to transfer technology from academia to industry } \\
\text { and write a formal final report, and submit to and acquire } \\
\text { approval from his/her advisor. }\end{array}$} \\
\hline $\begin{array}{l}\text { Contribution of Course to } \\
\text { Professional Component: }\end{array}$ & \multicolumn{2}{|c|}{$\begin{array}{l}\text { Students learn to design, implement, and test engineering } \\
\text { systems, cooperate with other team members, and prepare } \\
\text { technical reports. Statistical methods are used in data analysis. } \\
\text { A wide range of measurement techniques are used in } \\
\text { developing the system. }\end{array}$} \\
\hline \multirow[t]{11}{*}{ Grading Criteria: } & Subject Area & Percentage \\
\hline & Planning and Requirements & $10 \%$ \\
\hline & Analysis and Feasibility & $10 \%$ \\
\hline & Design and Development by using UDL & $15 \%$ \\
\hline & Implementation and Testing & $15 \%$ \\
\hline & Documentation & $10 \%$ \\
\hline & Presentation & $10 \%$ \\
\hline & Self Evaluation & $10 \%$ \\
\hline & Communication \& team work & $10 \%$ \\
\hline & Availability & $5 \%$ \\
\hline & Reflection & $5 \%$ \\
\hline Notes: & \multicolumn{2}{|c|}{$\begin{array}{l}\text { Anyone who needs an accommodation based on the impact of a } \\
\text { disability should contact Disable Student Services at 909-869- } \\
3333 \text { located in building 9, room 103. }\end{array}$} \\
\hline
\end{tabular}


3. Multiple forms of contact information is offered so students have varied ways to contact the instructor with questions or concerns as follows:
Professor's Name:
Dr. S. Monemi
Office location \& phone:
9-527, 909-869-2520
Email:
ssmonemi@csupomona.edu
Class time \& location:
MW 1:00-1:50 PM, Room 9-329
Office hours:
Monday, Tuesday, Wednesday 8:00 - 10:00 AM

\section{Representation}

On the representation side, multiple methods of expressing general course content utilizing different modes (visual, graphic, verbal, auditory, etc.) is provided so students have varied ways to access the course content. Also multiple ways of clearly identifying and explaining essential course concepts (lecture with guided notes, etc.) is offered. Accessibility in all course content and materials (accessible websites, captioned videos, e-textbooks, etc.) is provided. Many examples and/or illustrations of all major course assignments or activities are available to the students as follows:

1. Multiple methods of expressing general course content utilizing different modes (visual, graphic, verbal, auditory, etc.) are presented so students have varied ways to access the course content. Utilization of multiple methods of expressing general course content using different mode:

- Visual or graphic representation, for example: Presentation of previously successful project

- Short videos, for example: Video of related examples

- Suggestions for improvements, for example: Any ideas?

2. To provide multiple ways of clearly identifying and explaining essential course concepts (lecture with guided notes, etc.) such as:

$$
\begin{aligned}
& \text { How do I Represent Course Concept? } \\
& \begin{aligned}
- & \text { I lecture } \\
- & \text { Show and Tell } \\
- & \text { I provide handouts } \\
- & \text { I give examples } \\
- & \text { I refer to web sites } \\
- & \text { Reference textbooks } \\
- & \text { I distribute similar articles/papers/journals } \\
- & \text { Group discussions }
\end{aligned}
\end{aligned}
$$

3. To ensure accessibility in all course content and materials (accessible websites, captioned videos, e-textbooks, etc.) such as: 
How do I ensure accessibility in all course content and materials?

- I make my class notes available thru web

- I will have videos of previous projects available in CD/DVD

- I will have electronic copies of class notes available on my web site

4. To provide examples and/or illustrations of all major course assignments or activities such as:

How do I provide examples of course assignments?

- I will distribute a CD that contains all the examples related to their assignments

- I will provide some illustrations of a couple of related work so that the students can picture in their mind what the final product will look like.

\section{Engagement}

On the engagement side, varied instructional methods are offered to involve students in the learning process throughout the quarter (lecture, small group work, online assignments, class discussion, etc.). Natural support systems are encouraged (study buddy, partner work, study groups, etc.) in and outside of class. Alternatives for students on how they can participate or complete all major course assignments or activities are provided as follows:

1. To offer varied instructional methods to involve students in the learning process throughout the semester (lecture, small group work, online assignments, class discussion, etc.) such as:

How do I engage students in the learning process?

- Have them work in a small group

- Have them read related articles and ask questions

- Have them perform their individual assignments (research, planning, design, etc.) and report on it in the next meeting

- Ask each of them in what phase of the project they can make the most effective contribution

- Have them show demos where possible

2. To encourage natural support systems (study buddy, partner work, study groups, etc.) in and outside of class such as:

How do I encourage natural support system?

- Have them work as a group

- Also have them work as a sub-group

- Some group meetings in evenings or weekends

3. To provide alternatives for students on how they can participate or complete all major course assignments or activities such as:

How do I provide other alternatives? 
- Any ideas on how to do more in this area?

- What are some alternatives?

- Work in small groups to be more efficient

- Any suggestions?

\section{Expression}

On the expression side, a clear and specific feedback on assignments and encourage resubmission of assignments as appropriate is offered. Students are allowed to demonstrate their knowledge of subject matter through a variety of means (oral presentation, written report etc.). Use of assistive, adaptive or other technologies are encouraged to ensure that students can accurately express what they know. A clear guidelines and/or evaluation rubrics for all major course assignments or activities is provided. Finally, an assessment of the entire student's work is collected for the future course improvement and any challenges that the students may have as follows:

1. To offer clear and specific feedback on assignments and encourage re-submission of assignments as appropriate:

The instructor will use the following form and provide it online to each student for their assignment feedback. The students will evaluate others as well as themselves. When evaluations are not satisfactory, the instructor will have the students to rework the assignment and resubmit. Consequently another reevaluation will be given.

The students will:

- Fill out surveys at the beginning of the quarter

- Fill out surveys at the end of the quarter

The following is an example of a survey form given to the students:

\begin{tabular}{|l|l|l|}
\hline Evaluator Name & \multicolumn{2}{|l|}{} \\
\hline Team & \multicolumn{2}{|l|}{} \\
\hline Date & $\begin{array}{l}\text { 5= Excellent } \\
1=\text { Poor }\end{array}$ & $\begin{array}{l}\text { Comments } \\
\text { (required for each person) }\end{array}$ \\
\hline Criteria & & \\
\hline Hardware Knowledge & & \\
\hline Software Knowledge & & \\
\hline Leadership & & \\
\hline Communication & & \\
\hline Team Work & & \\
\hline Universal Design Learning & & \\
\hline TOTAL & & \\
\hline
\end{tabular}


2. To allow students to demonstrate their knowledge of subject matter through a variety of means (oral presentation, written report etc.) such as:

How do I ask students to express their knowledge?

- To give an oral report on weekly basis

- To present some working examples

- Charts, design flow graph, Design Algorithm

- To show a demo

- Object is moving forward

- Short quizzes

- Name and explain different phases of system development life cycle.

3. To encourage the use of assistive, adaptive or other technologies to ensure that students can accurately express what they know such as:

a. The students will use small circuit boards to build a workable prototype of the subsystem.

b. They will use Microsoft project to schedule and plan their work.

c. They will use power point to aid their oral presentation.

4. To provide clear guidelines and/or evaluation rubrics for all major course assignments or activities. I will use the following guidelines for evaluation of course assignments and activities:

\begin{tabular}{|l|c|}
\hline \multicolumn{1}{|c|}{ Subject Area } & Percentage \\
\hline Innovation ideas & $15 \%$ \\
\hline Planning and Requirements & $10 \%$ \\
\hline Analysis and Feasibility & $10 \%$ \\
\hline Design and Development & $10 \%$ \\
\hline Implementation and Testing & $10 \%$ \\
\hline Documentation & $5 \%$ \\
\hline Transfer of technology & $15 \%$ \\
\hline Presentation & $5 \%$ \\
\hline Self Evaluation & $5 \%$ \\
\hline Communication and team work & $5 \%$ \\
\hline Availability & $5 \%$ \\
\hline Reflection & $5 \%$ \\
\hline
\end{tabular}

\section{Project Case Study}

In fall quarter 2008, two students were enrolled in EGR 481, Project Design Principles and Applications. This project ${ }^{3}$ is to design an irrigation system that can be used to control up to 6 channel sprinkler system, with scheduling capability and wireless connection. Both students had some difficult times to grasp the technical issues and problems that may be associated with the design of the project. One of the students assigned to this project had a difficult time to 
visualize what the final product will look like and the other one could not comprehend how the components will be connected to each other. By using UDL concepts they decided to break it down to the following five sections:

- Visualization (UDL connection)

- Technical (Ability and Teamwork

- Organization (Team member)

- Economical (Funding)

- Scheduling

Visualization: Some students may have a hard time at the beginning of any project to visualize what the final product will look like until it is all over with. To build the entire project in some sort of physical model will help students to better visualize the project. This is almost the same thing as done with software simulation. Here is actually how the project is connected to UDL, by way of visualization. For this reason, the students had to build a model of the entire project so that they can visualize the entire project before it is actually built. They can see all of the interconnections and various components of the system. Figure 1 illustrates the entire "sprinkler system" project which was constructed by the students.

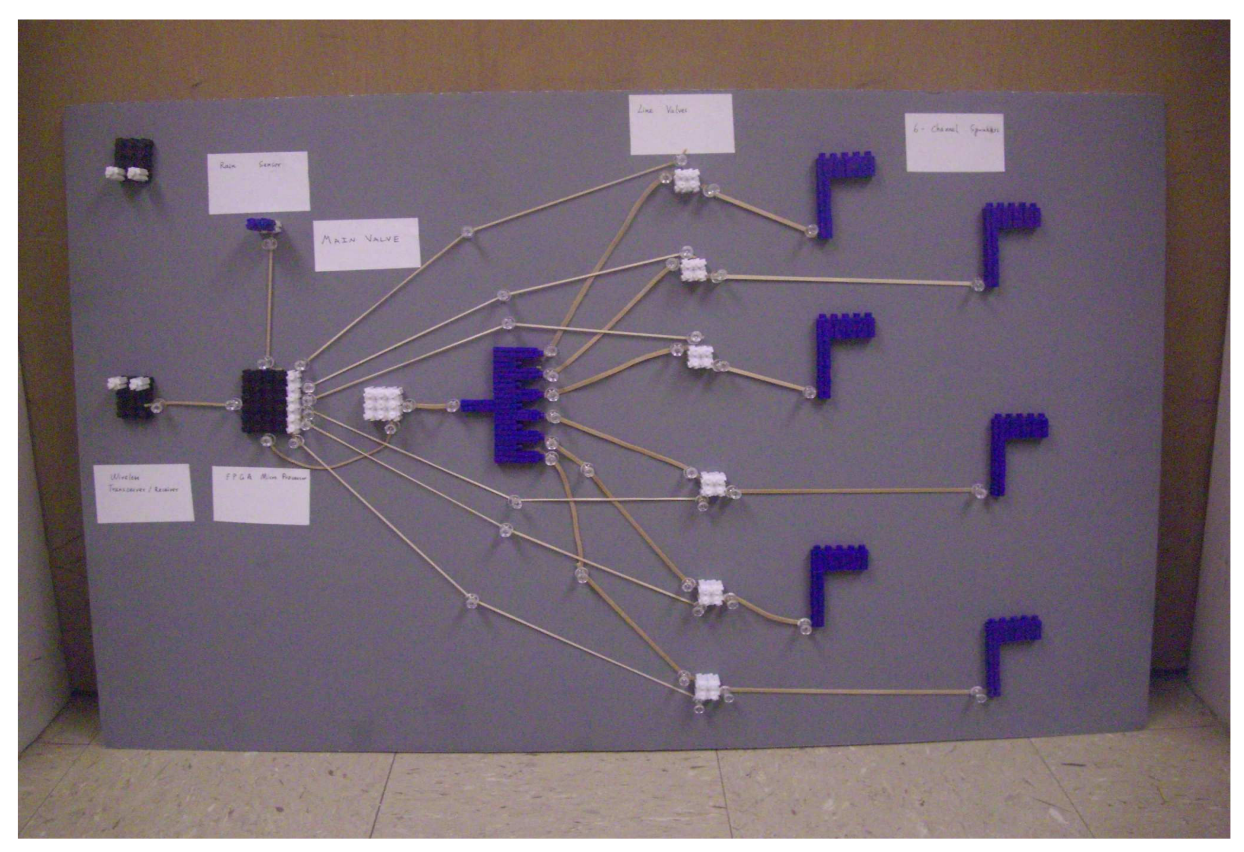

Figure 1- Visualization of the sprinkler system

Technical: To make sure of a successful completion of the senior project in time, the students had to evaluate their technical competency and available technologies used in this project. For this reason and by suggestion from their instructor, the students decided to go perform a Preliminary Design Review (PDR) first and discuss all the related issues and limitations; and 
then have the design completed in their Critical Design Review (CDR) where all of the important decisions at this point should be clearer to them.

The 6-channel valve controller of the irrigation system was built from a Xilinx Sparta FPGA board. Please see figure 2. The selection of this board was because of student's familiarity in their previous courses such as ECE 204 and 205. The language used to program this board is verilog, which a popular Hardware Description Language (HDL). A rain sensor is an add-on that shuts down the valve with it rains to save water. It can be found in most of the hardware stores, and the datasheet shows that it's very easy to implement. The user input from a remote control device that is already programmed in the system memory and in proper times is communicated to the valve system for proper operation of the sprinkler system.

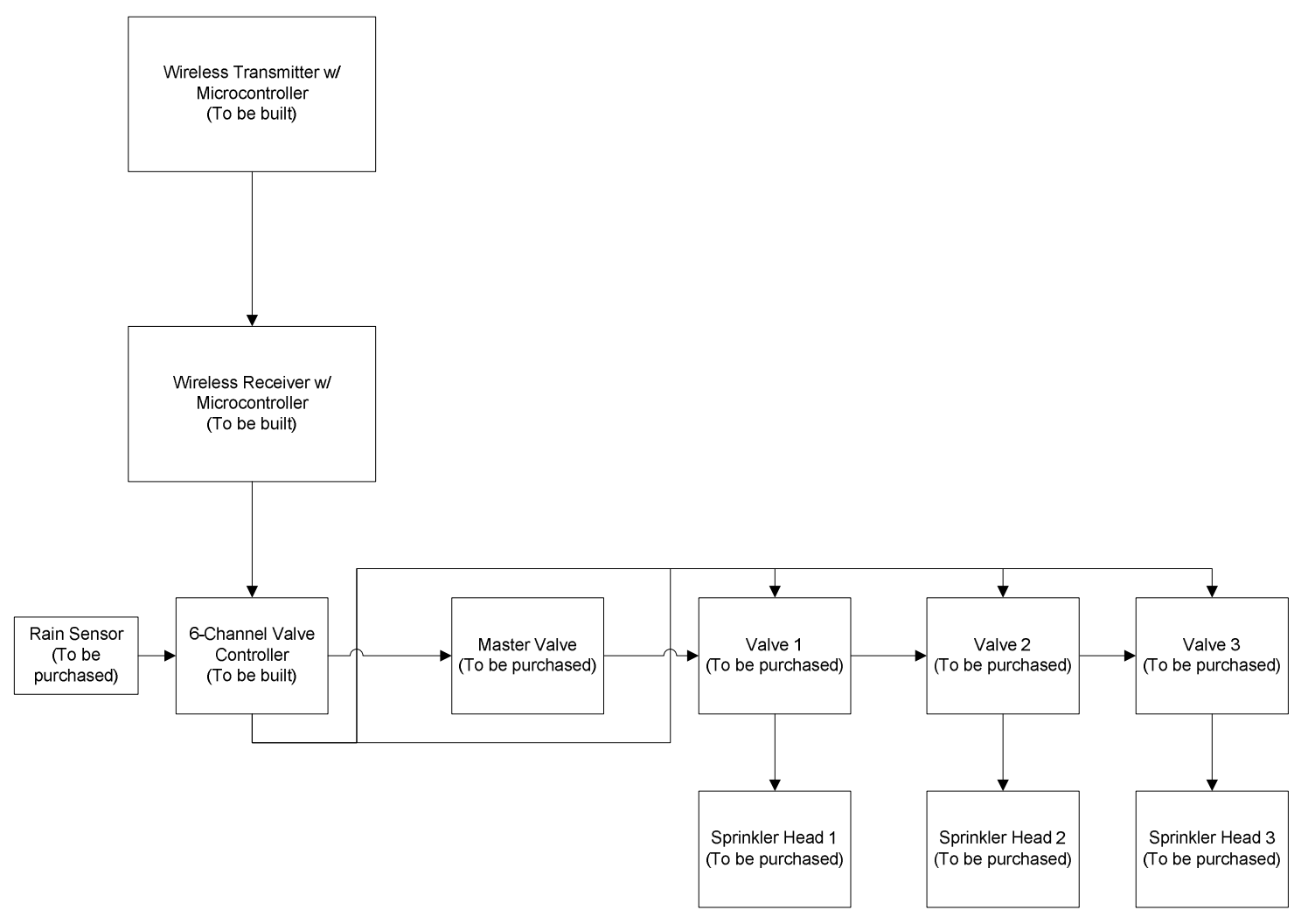

Figure 2- Block Diagram of the sprinkler system

Organization: There are two students in this senior project team that were both very devoted to the project. It was believed that with teamwork, they can make up the lack of bodies with their hard work and dedication. From the technical perspective, as discussed earlier, it was concluded that students are both competent to a successful finish of the project on time. The students worked on some parts together and other parts separately but were able to integrate the whole project at the end as one. 
Economical: This project requires two microcontrollers (one FPGA and one HC-11). The students have both boards from the previous classes (ECE 205L and 341L), so this saves them about $\$ 350$. The parts to be purchased are listed here with their prices.

\begin{tabular}{|c|c|c|c|c|c|}
\hline Item & Part Name & Part \# & Price & Quantity & Cost \\
\hline $\begin{array}{l}\text { Zone } \\
\text { Valve(s) }\end{array}$ & CP Series Sprinkler Valve & $\begin{array}{l}\text { CP-075 3/4" } \\
\text { FPT }\end{array}$ & $\$ 19.09$ & 6 & $\$ 114.54$ \\
\hline $\begin{array}{l}\text { Master } \\
\text { Valve }\end{array}$ & $\begin{array}{l}\text { ASVF Series Anti-Siphon Sprinkler } \\
\text { Valve }\end{array}$ & $\begin{array}{l}\text { ASVF-075 } \\
\text { 3/4" FPT }\end{array}$ & $\$ 29.00$ & 1 & $\$ 29.00$ \\
\hline $\begin{array}{l}\text { Rain } \\
\text { Sensor }\end{array}$ & RSD-BEx Rain Sensor & A61200 & $\$ 34.63$ & 1 & $\$ 34.63$ \\
\hline PVC Pipe & $\begin{array}{l}\text { Charlotte Pipe } 3 / 4 \text { In. x } 10 \text { Ft. PVC } \\
\text { Schedule } 40 \text { Solidcore Plain End Pipe }\end{array}$ & $\begin{array}{l}\text { Model PVC } \\
040070600 \\
\end{array}$ & $\$ 2.44$ & 3 & $\$ 7.32$ \\
\hline Sprinkler & $\begin{array}{l}\text { Rain Bird Impact Sprinkler (up to } \\
45 \mathrm{ft} \text { ) }\end{array}$ & $\begin{array}{l}\text { Model 2045- } \\
\text { PJ-08 }\end{array}$ & $\$ 6.29$ & 4 & $\$ 25.16$ \\
\hline \multirow[t]{3}{*}{ Sprinkler } & P5-R Black Bird Plus (20-41ft) & A30200 & $\$ 10.99$ & 2 & $\$ 21.98$ \\
\hline & $\begin{array}{l}\text { Male NPT, 3/4 In. Manual Valve, } \\
\text { Anti-Siphon }\end{array}$ & Model L4034 & $\$ 8.97$ & 1 & $\$ 8.97$ \\
\hline & & & & Total & $\$ 241.60$ \\
\hline
\end{tabular}

The total comes down to $\$ 241.60$ and that's about $\$ 120$ for each member. This is a fairly affordable project thanks to the low prices of commercial sprinklers and valves.

Scheduling: the students have three quarters to finish up this project. According to the syllabus, this project involves development, analysis, and completion of a detailed design leading to implementation of the system, writing and presenting the final report. To make sure the successful completion of the project, students broke down the project according to the criteria presented by the instructor and come up with a workable schedule. They believe that if they can follow up on the schedule time, they would have no problem finishing this project on time. In quarter 1 (fall 2008), they are going to work on "Planning and Requirements", "Analysis and Feasibility", initial stage of "Design and Development". This quarter is mainly for preparation of the project. In quarter 2 (winter 2009), they will focus on "Design and Development", "Implementation and Testing", which means in this quarter they have to build the actual system. In quarter 3 (spring 2009), they will try to wrap up the project by preparing "Documentation", "Presentation" and "Self-Evaluation". In this quarter, their main focus is going to be the presentation and demonstration of the project. The students used MS Project tool for scheduling and managing their entire project.

\section{Student's form for Assessment}

A comprehensive survey ${ }^{4}$ was distributed among the students. The form below contains part of the information collected during assessment: 
Please take a moment to complete this brief confidential survey that will help us understand how faculty can support students in the college classroom.

Course Name and Number:

Please tell us about yourself:

What is you gender?:

Male

Female

What is your age?:

18-22 23-27

28-37 38+

College level? Freshman

Declared or anticipated Major:

Do you have a disability?

Sophomore Junior

Senior Graduate Student

Yes No

If you choose to do so, please indicate your primary disability:

Visual limitation

Communication disability

Deaf and Hard of Hearing

Mobility limitation

Learning disability

Other Functional Limitations

Other

The following section of survey will reflect new changes made in the course by the professor:

Your professor will identify up to three specific changes they made to this course. As a student, what was the impact of these changes in terms of helping you learn or be more successful in this class?

Change \# 1:

Not Important Somewhat Important Very Important

Change \# 2:

Not Important $\quad$ Somewhat Important $\quad$ Very Important

Change \# 3:

Not Important Somewhat Important $\quad$ Very Important

What other aspects of this class (how they structured classes, created assignments, etc) helped you be successful as a student?

1.

2.

3.

What could your professor change in the future to help you be more successful as a student in this class? 1.

2. 


\section{Student's Responses and evidence of success}

The following assessment is the result of student's responses to the above questions:

Course Name and Number: EGR 481 Project Design Principles and Applications using UDL

Please tell us about yourself:

What is you gender?:

Males

23-27

Senior

College level?

Declared or anticipated Major: Electrical Engineering

Do you have a disability? $\underline{\text { Results }}$

If you choose to do so, please indicate your primary disability: None

Visual limitation

Communication disability

Deaf and Hard of Hearing

Mobility limitation

Learning disability

Other Functional Limitations

Other

The following section of survey will reflect new changes made in the course by the professor:

\begin{tabular}{lllll} 
& \multicolumn{3}{c}{ Results } & \\
Change \# 1: Preliminary Design Review (PDR) & (2) & Very Important & & \\
Change \# 2: Critical Design Review (CDR) & (2) & Very Important & & \\
Change \# 3: Visualization & (1) & Very Important & (1) Somewhat Important
\end{tabular}

What other aspects of this class (how they structured classes, created assignments, etc) helped you be successful as a student?

1. Student \#1 "The syllabus was well developed and made expectations mostly clear, I think this contributed to me successful completion of the project"

Student \#2 "The structure of meetings/assignments kept the group heading the right direction, otherwise I would have been lost"

2. Student \#1 "Weekly meetings were vital to keeping things running smoothly, it was well structured and organized"

Student \#2 "the meetings with the professor kept our meetings on task, good organization"

3. Student \#1 - Did not submit any comments

Student \#2 "Visualization of project made the project more attainable, otherwise I would have had a difficult time to picture what I was going to do"

What could your professor change in the future to help you be more successful as a student in this class? 
1. Student \#1 "It would be nice to have an explicit statement that says ECE must be involved in the project"

Students \#2 "More office hours"

2. Student\#1 "Starting weekly meetings early in the quarter would help

Student \#2 "More critical reviews of designs"

\section{Conclusion}

The project was evaluated and assessed in many different ways using UDL concepts versus nonUDL concept. It was clear from the assessment results that using UDL concept helped greatly the students with limited ability, hard to grasp, slow learner or thinker. Using UDL concept actually provided multiple and flexible methods of presentation to give students with diverse learning styles various ways of acquiring information and knowledge. The students with diverse background had alternative ways for demonstrating what they have learned, and finally by means of engagement they were challenged appropriately and motivated to learn.

The accomplishments of the students and their team works were superior. The instructor selected mixed students with different levels of experience in this project. The purpose was so that the experienced students can pass the technical expertise to the inexperienced students and demonstrate how team works should work in a diverse environment. It is very clear that teaching a course using concept of UDL will have some added values. For example, here are quotations from a couple of students of what they learn:

Student \#1:

"I learned a lot from this project. I had no idea what UDL was until I saw the visualization of the concept before I actually implemented it".

"There are going to be technical difficulties but they are not beyond our scope, and we are competent to overcome them."

Student \#2:

"I learned to work with team members regardless of any limitation that a team member might have, now I know how to deal with the problems."

"The lack of bodies can be made up with hard work and dedication."

\section{References}

1. http://www.advocacyinstitute.org/UDL

2. http://www.cast.org/research/udl/index.html

3. Wei Cong Pan and Edward Varnado "Sprinkler System", Senior Project 2008-2009

4. Sonoma State University Project on Universal Design Learning, 2008 